\title{
Sport Knowledge Management and Its Role in Promoting the Electronic Marketing Decision Making Process
}

\author{
Hasan Mohammad Al-Khaldi ${ }^{1}$ \\ ${ }^{1}$ Sport Management faculty of physical education and sport sciences, Al-Hashemiah University, Jordan \\ Correspondence: Hasan Mohammad Al-Khaldi, Sport Management faculty of physical education and sport \\ sciences, Al-Hashemiah University, Jordan. E-mail: h_khaldi74@hotmail.com
}

Received: February 13, 2014 Accepted: May 13, 2014 Online Published: June 24, 2014

doi:10.5539/ass.v10n14p8 URL: http://dx.doi.org/10.5539/ass.v10n14p8

\begin{abstract}
This study aimed to know the sport knowledge management and its role in promoting the electronic marketing decision making process from the view point of the working managers at the higher council for youths and sport in Jordan. Study sample selected from all the working managers at the higher council of youth (55) managers. The study used knowledge management questionnaire, the content validity of the study was regarded using professors and experts. The reliability was obtained via Cronbach's Coefficient Alpha $\alpha=0.90$.

The result showed that there is a significant difference in knowledge management and its role in promoting the electronic marketing decision making process. Also the majority of the study sample understand the importance of knowledge management and the necessity of the presence of the explicit and implicit. Furthermore the study found that the necessity for innovation and creativity, confronting change resistance concept in order to keep apreast with the advanced countries in the management field including the sport knowledge management.
\end{abstract}

Keywords: sport knowledge management, marketing decisions, electronic marketing

\section{Introduction}

The future of the public institution and including the sport institution depends on the extent of perceiving and investing its resources to increase their competitive advantage, attempting to armed with knowledge approach and management that considers the newest managerial concept after perceiving knowledge as a vital presence in achieving the institution goals generally and one of the rare and important resources for the human in this large world, and considers the electronic weapon to achieve the distinguish success.

Knowledge management is the acquisition, sharing, and use of intelligence, understanding, and expertise within a sport organization to aid in the accomplishment of tasks, processes and operations and to enhance the performance through different methods and techniques (Schwarz et al., 2010; Revilla et al., 2009).

Many sport organizations in the world with an emphasis on implicit and explicit knowledge are seeking to increase the effectiveness and performance levels. The concept knowledge management is linked with the known economic base the rare available knowledge in the society, and as expressed by the economists these capabilities and Talants and personal qualities should be effectively exploited to the third world's countries (Stenmark, 2002).

Many specialists in the knowledge management have pointed that its processes summarize in the following: Knowledge Identification, Determining the knowledge goals and Knowledge storing. Knowledge dissemination. (Heisig et al., 2001; Gherardi, 2006).

.Knowledge can be explicit or implicit that is available in the individuals minds and depends on their experience, skills, intitutions and their ability in thinking, it is available in the form of meaningful information.

Knowledge management is one of the most innovative and important ways to improve efficiency and managerial perceptions in sporting organizations. Managerial leaders should effectively and with competency deal with investing the knowledge capabilities and energies in the electronic marketing decision making using the capabilities of the society to achieve progress and prosperity.

The decision is the selection from among a set of offered alternatives to solve a problem or a crisis, or to run a specific work after determining the strengths and weakness elements for each alternative to prepare the alternatives and selecting the best. 
EMarketing or electronic marketing decision refers to the application of marketing principles and techniques via electronic media and more specifically the Internet. Because the electronic marketing decision represents selecting a field or specific activity performed by the institution that demands the employment of most available resources and assets in order to gain the maximam possible revenue during spesefic period of time, and this means the extent of success or failure of the institutions in achieving their goals, so the public institution including the sport sport institutions will be more successful in their insestments if become able to depend on the knowledge income (Marquardt, 2002).

Decision making process is the thinking process of picking a choice. It can be regarded as the mental or cognitive processes resulting in the selection of a course of action among several alternative scenarios. It is a process to conceptualize, Decision making structure requires a logical and objective consideration of all decision-making factors involved. Since any individual, collective, private, institutional manual \& electronic decisions should be based open the knowledge through determining the problem, collecting the relating information, and the factors that are linking with resolving this problem, and the process evaluating the different alternatives and selecting the best alternative.

\subsection{Research Problem}

Significant differences have emerged about how to look at the knowledge management concept, its importance and value in sport filed. In the advanced societies we see the greater interest in the topic knowledge management, and higher care about how to use and distribute it, and this interest is less in the developing countries, since the topic did not receive the due interest from the researchers in the sport field specifically.

Sport institutions are still suffering from the difficulty linking the scientific and practical concepts between the storage of the human resources knowledge and the electronic marketing decision making process, since the process decision making is one of the hardest tasks in the sport institutions, because the good manager's success does not appear unless after making the difficult decisions needs amply scientific knowledge based on facts and data to deal with the problem and adopting the knowledge methods in the decision making process.

The main purposes of this study is to determine the relationship between sport knowledge management and the process marketing decision in the sport field, and to determine the relationship between the explicit and implicit knowledge and the process marketing decision making in the sport field.

\subsection{Research Questions}

The current study tries to answer the following main questions:

Is there any significant relationship between sport knowledge management and the process marketing decision making in the sport field?

Is there a statistical significance relationship between the explicit knowledge and the process marketing decision making in the sport field?

Is there a statistical significance relationship between the implicit knowledge and the process marking decision making in the sport field?

\section{Materials and Methods}

\subsection{Participants and Procedure}

Study population consists of all the managerial employees at the higher council for youths and sport, (105) employee. Study sample consisted of the managerial employees at the higher council for youths and sport, (55) managerial employee (Amman-Jordan).

\subsection{Procedures and Research Instrument}

Research variants are: knowledge management as independent variant, electronic marketing decision as dependant variant.

The instrument included sport knowledge management questionnaire was designed by the author utilizing a five point Likert scale ranging from " 1 = strongly disagree" to " 5 = strongly agree".

Instrument Validity: The instrument included sport knowledge management questionnaire. The content validity of the study was regarded using professors and experts. to make sure that the language used is correct, and the extent of the items relevance, modifications were made in the light of the arbitrators directions.

Instrument Consistency: To insure the reliability of the questionnaire, reliability coefficients were measured by conducting Cronbach-alpha. The reliability values reached (0.90), for all dimensions which is accepTable for the 
scientific research purpose.

\section{Results}

Data resulted from description of knowledge management and its role in promoting the electronic marketing decision making process show that average of knowledge management was (31.2) and average of capturing \& keeping knowledge was (3.33). Applying knowledge had the highest grade(3.68) and acquisition knowledge had the minimum grade (3.05). whereas Transferring knowledge was (3.09) as can seen from the Table 1.

Table 1. Knowledge management processes average scores and its role in promoting the electronic marketing decision making process

\begin{tabular}{lll}
\hline Titles of Processes & Average & SD \\
\hline Acquisition knowledge & 3.05 & 0.50 \\
Capturing \& keeping knowledge & 3.33 & 0.66 \\
Applying knowledge & 3.68 & 0.55 \\
Transferring knowledge & 3.09 & 0.48 \\
Knowledge management & 3.12 & 0.50 \\
\hline
\end{tabular}

The results indicate that $(80.10 \%)$ from the participants were perceived the importance of the explicit knowledge represented by the available information in the sport initiations and structure, and $(11.20 \%)$ were uncertain in their answers and $(8.60 \%)$ were strongly disagree with the knowledge management importance the mean was (3.77) and standard deviation (0.47). Table 2 shows the average and standard deviations for the explicit, implicit knowledge management and the process electronic marketing decision making.

Table 2. The averages and standard deviations for the types of knowledge management and the process electronic marketing decision making $\mathrm{N}=55$

\begin{tabular}{llll}
\hline Types of Knowledge management & Mean & S.D & Average \% \\
\hline Explicit knowledge & 3.77 & 0.47 & $80.10 / 8.60$ \\
Implicit knowledge & 3.08 & 0.60 & $59.11 / 40.01$ \\
Process electronic marketing decision making & 3.88 & 0.48 & $82.12 / 3.50$ \\
\hline
\end{tabular}

According to the implicit knowledge $(59.11 \%)$ of the participants were completely uncertain about the importance of the experiences and the capabilities that the individuals possess, and $(40.01 \%)$ of the research sample were uncertain in their answers, with mean (1.98) and standard deviation (0.50).

The study finds that $(82.12 \%)$ of the participants agree upon the active role of the process the optimal electronic marketing decision making that determines the destiny of any sport institution, and $(4.33 \%)$ strongly agree but $(3.50 \%)$ of them disagree, and $(9.44 \%)$ were uncertain about the importance of the electronic marketing decision making in determining the sport institutions with mean (3.88) and standard deviation (0.48).

Spearman's rank correlations were calculated to find the relationship between sport knowledge management and the process marketing decision making in the sport field, strong positive correlation were found $(\mathrm{r}=.71 \mathrm{p}$ $=.001$ ).

Result showed a significant strong positive correlation between explicit knowledge and the electronic marketing decision making process were found in the sport field $(\mathrm{r}=.66 \mathrm{p}=.002)$ at level $(\mathrm{p}<0.05)$. also positive correlation between the implicit knowledge and the process marking decision making in the sport field $(\mathrm{r}=.54 \mathrm{p}$ $=.005)$.

Table 3. The relationship between the sport knowledge management and the process electronic marketing decision making in sport field

\begin{tabular}{lll}
\hline Variables & Spearman correlation coefficient & Significance level $(\mathrm{p}<0.05)$ \\
\hline Explicit knowledge & .66 & .002 \\
Implicit knowledge & .54 & .005 \\
Sport knowledge management & .71 & .001 \\
\hline
\end{tabular}




\section{Discussion}

After conducting the relevant statistical processes in order to answer the study's questions and in the light of the results reached,the researcher wanted to know if there is a significant relationship between sport knowledge management and the process marketing decision making in the sport field?

Referring to our findings there were a strong relationship between the sport knowledge management and the process marketing decision making in the sport field. The researcher explains that most of the research sample agree upon the presence of correlation between knowledge management and the sport electronic decision making, since knowledge management is the set of values, cultures, processes, procedures, and concepts that based upon the discussions marketing field or in other fields, and since the knowledge management is on of the processes acquiring, storing, disseminating, distributing and generation, so the sport knowledge management, is based upon acquiring the marketing knowledge, and how through it is possible to share it with other through innovative and creative processes, by this the explicit and implicit knowledge greatly contribute to making the electronic marketing decision which is reality a goal, procedures and methods linked to the sport business market,. This is agreed with (Hansell, 2001; Haubl \& Trifts, 2000; Coakes, 2003; Coakes et al., 2002; Handzic, 2004), who have assented that the electronic marketing decision needs skills, and high techniques should be available to the knowledge workers.

A significant correlation between the explicit and implicit knowledge and the process the electronic marketing decision making were found . which refer to the majority of the study sample are trying to refute the concept change resistant and eliminate it especially in the sport society which lacks from the administrative side that it is classical and routine, and those in charge of the work rejecting the innovative and creative ideas, since the study sample see the necessity to link knowledge management with the marketing electronic decision making, especially that this demands the nature and the specification of work, since the workers inside the sport institution are linked together by the internet, this means that it is not the condition that the employee should practice his work from the office, and not constraint to the formal work hours, so the standards and the measures for the individual's success at work are different.

Also the researcher sees that the current sport marketing processes contribute to solve some of the problems, but the ambition of the management experts is limitless, since the success in making the marketing electronic decision making in the sport field and in the frame of the political and social changes that the world is going through consider the turning point in the process marketing the sport product either in the instrument player or attendance ticket to a match, because the sport marketing process is no longer link to a drink or advertising the product, since the sport knowledge management with its processes especially in the acquisitions, distribution and generating link with the electronic marketing decision, some of which are linking with the sport institutions, in vesting the facilities, service, advertisements, donations and contracts, TV and Radio podcasting, champion making, management programs. The product reaches the consumer in the form and the knowledge faster through the electronic channels comparing to other means and techniques (Wolfinbarger \& Gilly, 2001; Bickart \& Schindler, 2001).

\section{Conclusion}

It is clear that sport knowledge management with what it implies of concepts whether explicit or implicit and through the knowledge and the information in the sport institution, or through the skills and experiences in the process the successful electronic marketing decision making that makes the sport in institution acquired the unique competitive position enables it to confront the challenges in to days world.

The knowledge approach is the important element to practice the administrative activities at the sport institution, not only in problem solving, but also in ghe electronic marketing decision making.

The majority of the research sample agree about the importance of promoting the electronic marketing decision making through following the scientific methods.

The real and actual interest by the sport institutions in the knowledge management (its processes) since it became today the real capital for the technical and financial resources to support the competitive advantage in the shadow of the challenges at the managerial area. There is the necessity to interest in the explicit and implicit knowledge, and the availability of the means and the new methods in the possibility to distribute the work groups.

It is important to use the modest and the up- to date methods in the process the employment of the electronic marketing decision through determining the goal, gathering information, providing the alternatives and selecting the best wing the creating element. 


\section{References}

Bickart, B., \& Schindler, R. M. (2001). Internet Forums as Influential Sources of Consumer Information. Journal of Interactive Marketing, 15(3), 31-40. http://dx.doi.org/10.1002/dir.1014

Coakes, E. (2003). Knowledge management: Current issues and challenges. Hershey, PA: IRM Press. http://dx.doi.org/10.4018/978-1-931777-51-3

Coakes, E., Sugden, G., Russell, S., Camillieri, J., \& Bradburn, A. (2002). Managing tacit knowledge in knowledge-intensive firms: Is there a role for technology? In E. Coakes, D. Willis, \& S. Clarke (Eds.), Knowledge management in the sociotechnical world: The graffiti continues (pp. 153-169). London: Springer. http://dx.doi.org/10.1007/978-1-4471-0187-1_15

Gherardi, S. (2006). Organizational knowledge: The texture of workplace learning. Malden, MA: Blackwell Publishing.

Handzic, M. (2004). Knowledge management: Through the technology looking glass. Toh Tuck Link, Singapore: World Scientific Publishing.

Haubl, G., \& Trifts, V. (2000). Consumer Decison Making In Online Environments. MarketingScience, 19, 4-21. http://dx.doi.org/10.1287/mksc.19.1.4.15178

Heisig, P., Mertins, K., \& Vorbeck, J. (2001). Knowledge Management. Concepts and Best practices in Europe (2nd ed.). ISBN 3-540-00490-4. Springer-Verlog. Berlin Heidelberg. New York.

Marquardt, M. J. (2002). Building the learning organization: Mastering the 5 elements for corporate learning (2nd ed.). Palo Alto, CA: Davies-Black Publishing.

Revilla, E., Rodriguez, B., \& Prieto, P. (2009). Information technology as knowledge management enabler in product development: Empirical evidence. European Journal of Innovation Management, 12(3), 346-363. http://dx.doi.org/10.1108/14601060910974228

Schwarz, E., Hall, S. A., \& Shibli, S. (2010). Sport facility operations management: A global perspective. Burlington, MA: Butterworth-Heinemann.

Stenmark, D. (2002). Information vs. Knowledge: The Role of Intranets in Knowledge Management. Proceedings of the 35th Hawaii International Conference on System Sciences (HICSS2002), Hawaii, USA.

Stnemark, D. (2002). Sharing Trait Knowledge: A case study at Volvo. In S. Barnes (Ed.), Knowledge management systems, theory and practical (pp. 36-48). London: Thomson Learning. UK.

Wolfinbarger, M., \& Gilly, M. C. (2001). Shopping Online for Freedom, Control and Fun. California Management Review, 43(2), 34-56. http://dx.doi.org/10.2307/41166074

\section{Copyrights}

Copyright for this article is retained by the author(s), with first publication rights granted to the journal.

This is an open-access article distributed under the terms and conditions of the Creative Commons Attribution license (http://creativecommons.org/licenses/by/3.0/). 